\title{
Ex-Ante Asymmetric Regulation and Retail Market Competition: Evidence from Europe's Mobile Industry
}

\author{
Edmond Baranes $^{1 *}$, Cuong Hung Vuong ${ }^{2}$ \\ ${ }^{1}$ LAMETA, University of Montpellier I, Montpellier, France \\ ${ }^{2}$ International University, Hochiminh City, Vietnam \\ E-mail: "edmond.baranes@univ-montp1.fr \\ Received March 16, 2011; revised June 20, 2011; accepted June 28, 2011
}

\begin{abstract}
The aim of this paper is to assess the impacts of ex-ante asymmetric mobile termination rate regulation on ex-post market competition in the Europe's mobile industry. Two regulatory instruments associated with the asymmetry between operators are implemented, namely glide path regulation and asymmetric regulation. The first regulatory device is to gradually decrease asymmetric treatment between mobile and fixed network operators while the second one is associated with asymmetric flexibility in setting MTRs between European mobile operators. With different model specifications, our study demonstrates that when the MTRs are regulated to lower levels, later entrants are likely to cut retail prices to gain more subscribers, and resulting in lower average national service prices. Furthermore, we find that asymmetric regulation plays a positive role on entrant penetration as well as the competitiveness of Europe's mobile markets.
\end{abstract}

Keywords: Competition, Asymmetric Regulation, Mobile Termination Charges

\section{Introduction}

The aim of this paper is to present empirical evidences on the regulatory success in promoting competition in the Europe's mobile telephony sector via setting mobile termination rates (MTRs). Precisely, during the liberalisation process in the Europe's telecommunications, two regulatory instruments associated with asymmetry between market players are identified, namely glide path regulation and MTR asymmetric regulation. Generally, because of a long-time presence and almost full market coverage, the first type of MTR regulation obliges the incumbent fixed network operator to provide interconnections at, naturally, cost-based level. Meanwhile, mobile network operators (MNOs) are allowed to charge above-cost termination rates. Because MTRs are then set by MNOs at excessively high levels thanks to their bottleneck, glide path regulation is therefore implemented. Particularly, glide path regulation is to gradually decrease asymmetric treatment between mobile and fixed network operators by lowering the MTR levels to costs of providing interconnection services. Indeed, in its draft recommendation on termination rates, the European Commission [1] asserts that "setting a common approach based on an efficient cost standard and the application of symmetrical termination rates would benefit end-users in terms of lower retail prices". To this end, European Regulatory Group also proposed to fix MTRs at a symmetric rate calculated by a relevant National Regulatory Authorities (NRAs) [2]. As a result, an important issue for European regulators is to provide a complex analysis on whether glide path regulation might enhance competition across the Europe's mobile markets.

This is an interesting regulatory issue for several reasons since the optimal level and the risks of high MTRs in competition between MNOs have been discussed extensively in economic studies. Arguably, although high MTRs might be appropriate to increase social welfare according to the Ramsey principle, it has already been acknowledged that regulatory implementation in practice is extremely difficult because of overloaded information. For the sake of mobile network development, a Pigovian tax on termination rate is useful to enhance the positive externalities from having a new mobile subscriber. Specifically, the important seminal papers by [3-5] provide a general framework to study competition between interconnected networks and the role of access charge setting. In this literature, the principal question is whether networks may use termination charges as a collusive tool to soften competition in the downstream market. These 
papers started the debate by pointing to the fact that high termination rates increase retail prices when operators compete only in usage prices. This conclusion is reversed when operators compete with more sophisticated pricing strategies by using for example two-part tariffs or on-net and off-net price discrimination. Following these seminal papers, a broad literature has been developed by relaxing different modeling assumptions and leads to the general conclusion that operators might coordinate low termination rates whether networks are not too asymmetric [6,7]. This has a crucial policy implication since this conclusion suggests that low termination rates serve as a collusive device with a prerequisite is that operators use non linear pricing [8]. In other words, in the mobile industry, high termination rates might be associated with low retail prices for mobile customers, and that pressing down MTRs by glide path regulation might lead to the socalled "waterbed effects".

While waterbed effect is broadly analysed at theoretical level $^{1}$, empirical works have not been the object of sufficient attention. For this reason, [10] provide a useful empirical study concerning the existence of the waterbed effect in the mobile market by testing the impact of lower MTRs on service prices of the two largest MNOs in each OECD country. Their main finding is that there is strong evidence of a waterbed effect, i.e.: a decrease in MTRs necessarily raises MNO tariffs. Additionally, the change in MTRs slightly impacts MNO profitability, suggesting that the waterbed effect is not complete ${ }^{2}$. Moreover, from the viewpoint of regulatory authorities, particularly New Zealand's Competition Commission, the waterbed effect is unlikely to occur because the dynamics of a competitive market prevents significant changes to mobile service and handset prices ${ }^{3}$.

The second regulatory instrument, namely MTR asymmetric regulation, is associated with asymmetric regulated MTR levels between mobile operators. Particularly, because of entry delay in the mobile industry, an early entrant could generally enjoy "first mover advantage" and hence obtain higher market share than later entrant [12]. Hence, smaller MNOs are allowed to set relatively higher MTR than larger MNOs to overcome the incumbency inherent advantage. In other words, European asymmetric regulation is used to protect and support new entrants against the established service providers to cre-

\footnotetext{
${ }^{1}$ The See, for example, [9] for a more general framework showing how waterbed effect depends on the degree of product substitutability.

${ }^{2}[11]$ with the data on the European mobile telephony also find that operator EBITDA were insignificantly affected by the MTR regulation. ${ }^{3}$ Paragraph 12 in the Draft Report on whether mobile termination should become a designated or specified service, New Zealand's Competition Commission, 18th October 2004,

http://www.comcom.govt.nz/IndustryRegulation/Telecommunications/ Investigations/MobileTerminationRates/reportsandsubmissions.aspx\# 227
}

ate a "level playing field" to achieve sustainable long-run competition between infrastructure MNOs.

In principle, the MTR asymmetry should be regulated at a reasonable level, and based on exogenous factors which are outside firm control on both backward-looking and forward-looking perspectives [2]. Precisely, the former refers to the entry timing delays, high cost due to spectrum allocation. Meanwhile the latter would include an analysis of potential operator strategic behaviours in the retail market, especially the distortions due to the above-cost MTR levels ${ }^{4}$. Despite this consistent principle, we shall see that the setting of individual MTR levels varied greatly among MNOs and among Europe's members. Regarding economic analysis, based on the basic framework of [4,5,13-15] predicts that around the cost-based MTR, a small sized network entrant can lower retail price to gain market share thanks to the wholesale profit implied by MTR asymmetric regulation. In response, the incumbent also lowers its price, resulting in lower service price in the retail market ${ }^{5}$.

This paper is therefore to provide an empirical analysis of the success of European MTR regulation on two dimensions: late entrant penetration and average national service prices, taking into account both MTR regulatory instruments. In precision, in first empirical test we find that MTR regulation significantly boosted entrant penetration during the 2002-2006 period across the Europe's mobile markets. In the second test, we can show that average mobile service prices included higher MTRs, that is by lowering MTRs by one percent, average mobile service prices could decrease as much as 0.27 percent depending on the model specifications and estimation techniques. Intuitively, since smaller MNOs are usually the last market entrants, they have strong incentives to increase their customer bases to benefit from scale economies. Furthermore, under asymmetric regulation, entrant could gain relatively higher wholesale revenues which are proportional to their market share. With this in mind, when the MTRs were regulated to lower levels, it was more likely for the later entrants to undercut retail prices to gain more market shares. Moreover, lower MTRs strengthen incentives to increase client bases since their profits are more dependent on the retail markets, hence increasing with their penetration rates. Consequently, they competed more aggressively to gain new subscribers, intensifying the competitiveness of the European mobile markets.

\footnotetext{
${ }^{4}$ This approach is indeed similar to the analysis of European merger control, and is under consideration of the French NRA. (See ARCEP 2009, Decision 08-1176. Available at:

http://circa.europa.eu/Public/irc/infso/ecctf/library?l=/france/adopted measures/fr20080812/08-1176pdf/_FR_1.0_\&a=d)

${ }^{5}$ See [13] for the discussion about the necessity of asymmetric regulation in Europe.
} 
The rest of the paper is laid out as follows: section 2 describes variables and data across Europe's mobile telephony. Section 3 is devoted to the empirical test for the relationship between MTR regulation and entrant penetration. Section 4 is then dedicated to an explicit analysis of the regulatory impacts on the competitiveness of European mobile markets. Section 5 presents concluding remarks.

\section{Data and Econometric Variable Descriptions}

With limited data and to ensure consistency among data, annual data is collected from thirteen countries in Western Europe with similar economic and regulatory environments (Germany, Netherlands, Austria, Belgium, Spain, Finland, France, Greece, Ireland, Italy, Portugal, Sweden, UK) (country level) and from twenty five late MNOs (operator level). The late entrant MNOs is defined as the main infrastructure MNOs using GSM technology in Europe with small market shares, excluding historic incumbents and early entrants with high market shares during the considered period. Their names are listed in the appendix.

\subsection{National Average Prices of Mobile Services} (P)

Due to the complexity of mobile tariffs offered in Europe's mobile markets, it is obviously impossible to collect all data, especially information on non-linear tariffs, which are mainly composed of subscription fees and per minute call price, and the levels of handset subsidies. Fortunately, data on average price for one minute of mobile outgoing traffic in each country can be obtained from QUANTIFICA ${ }^{6}$ for the period 2002-2006, which is calculated as follows:

$$
P_{c, t}=\frac{\text { Voice_revenues }_{c, t}}{\text { Voice_traffics }}
$$

where: Voice_revenues ${ }_{c, t}$ is the total revenues from outgoing mobile voice services in country $c$, and Voice_traffics ${ }_{c, t}$ is total mobile outgoing traffics generated within the correspondent year

Therefore, $P_{c, t}$ is a good proxy for competitiveness in Europe's mobile market since it takes into account the impacts of all main infrastructure MNOs players with different commercial strategies and real market demands in each country without studying individual nonlinear tariff packages.

\footnotetext{
${ }^{6}$ QUANTIFICA provides telecommunication data on demand at www.
} quantifica.fr

\subsection{Mobile Termination Rates (MTR)}

The reports on European regulatory implementation packages provide data about average MTRs for each operator in the EU from 2002 to 2007. To calculate average MTR for each country, it can be weighed with corresponding operator market shares ${ }^{7}$.

In general, average MTRs in country $i$ can be formulated as:

$$
\text { Average_MTR }=\sum_{j} \alpha_{i j} M T R_{i j}
$$

where, $M T R_{i j}$ denotes the termination rate for operator $j$ in country $i$ and $\alpha_{i j}$ the market share of operator $j$ in country $i$.

Figure 1 shows that, from 2002 to 2006, both average service prices and MTRs decreased together. Precisely, during the considered period, average service prices dropped from twenty four to eighteen euro centimes while average MTRs reduced by seven centimes to eleven euro centimes in 2006. Therefore, it seems that average service prices and termination rates at country level are positively liked in the Europe's mobile industry.

\subsection{Penetration of the Late Entrants (PEN)}

Late entrant penetration is also obtained from QUANTIFICA for the period 2002-2007. Figure 1 shows that their total penetration rates steadily surged from 110 million in 2002 to almost 180 million in 2007. This suggests that the late entrant retail prices might have actually decreased relatively with early entrant prices during this period.

\subsection{Market Concentration (HHI)}

The HHI index is widely used in economics research and in European competition analysis. The HHI index is proportional to the total sum of the square of market shares of all market players in an identical market. Mathematically, $\mathrm{HHI}_{c}$ in country $\mathrm{c}$ with $j$ operators is calculated as:

$$
H H I_{c}=\sum_{j=1}^{J}\left(\alpha_{j}^{2}\right) \times 10000
$$

where, $\alpha_{j}$ is the market share of operator $j$ in country c.

Obviously, the more concentrated a mobile market, the higher the difference market shares between MNOs operating in that country. The market with the highest degree of competitiveness is when firms have similar market

${ }^{7}$ In France, the Bill and Keep regime between mobile operators was used until 2004, so the French average MTRs in this study are, in fact, fixed-to-mobile termination rates. 


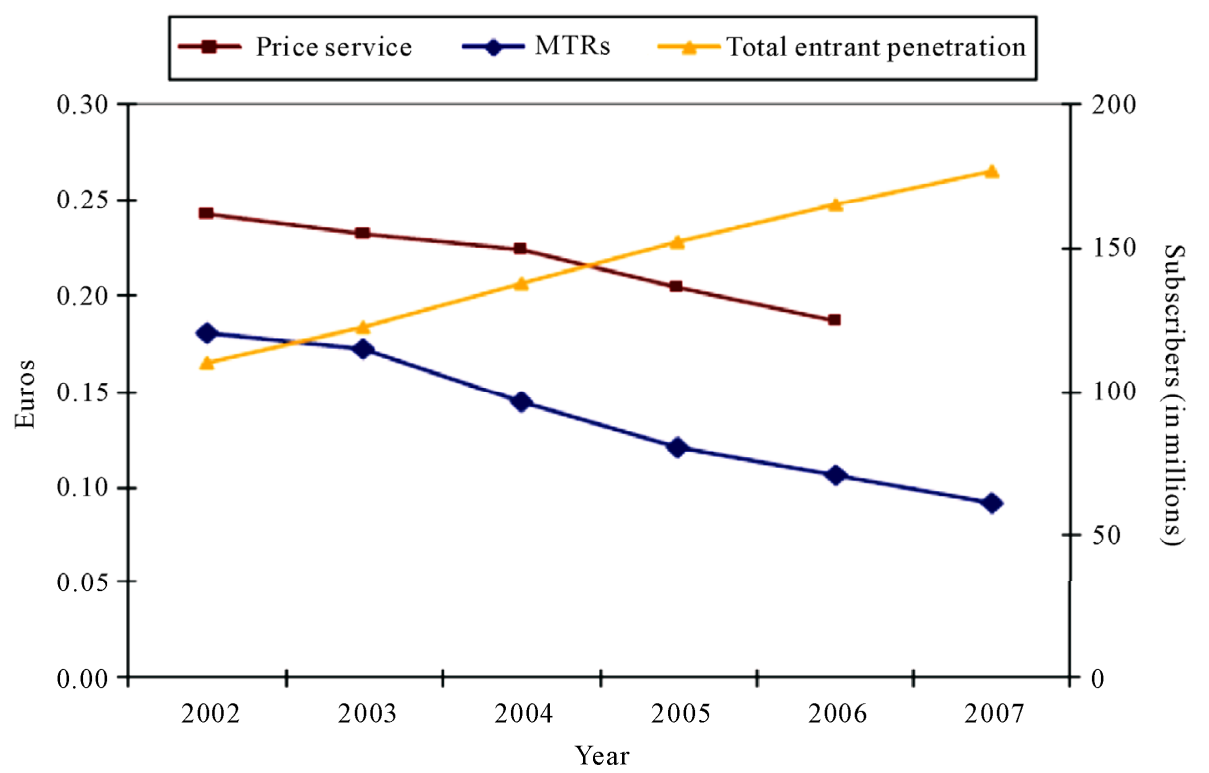

Figure 1. The average service process, the average MTRs and the total subscribers of the late entry operators (Source: QUANTIFICA and the european commission).

shares, all else being equal.

Figure 2 reports the HHI index in thirteen European countries from 2002 to 2007 in the sample. It is apparent here that there was a gradual decreasing trend in the level of market concentration with few exceptions where mergers between mobile operators occurred ${ }^{8}$ or where market shares of MNOs were almost stagnant as France.

\subsection{Number of Operating Years (YOE)}

This variable counts the number of years a firm has operated in the market since its first launch of mobile services. Since penetration is typically accumulated overtime, it can be expected that the longer time of market presence, the more likelihood for the MNO to have higher subscribers [5]. In fact, Figure 3 illustrates that the average late entry operator could acquire as many as four million additional mobile subscribers after five years from 2002 to 2007.

\subsection{Asymmetric Regulation Index (AR)}

As discussed earlier, in the European context, asymmetric regulation in wholesale markets is widely adopted and that later entrants can set higher termination rates than the earlier ones. This type of regulation is to promote competition in the retail mobile markets as ex-post entry profits are higher and hence to increase their penetration. Although this type of regulation is obviously an appropriate regulatory tool to help late entry MNOs es-

\footnotetext{
${ }^{8}$ For example, Telfort was bought out by KPN, the Netherland's in-
} cumbent operator, in 2005. tablished during the transition process, its implementation in practice can be debatable from economic efficacy perspective [16]. To increase the estimation robustness, one should employ an indicator to reflect the entrant benefits from the asymmetric regulation. In the simplest form, it can mean differences in MTRs between infrastructure MNOs in the relevant market. From economic theory, asymmetric regulation benefits should also depend highly on the market positioning of the market players and hence are likely to be proportional with the operator market shares ${ }^{9}$. Furthermore, since there are a number of MNOs in each European mobile market, it is pertinent to account for the relative market shares of the market players. Then, the construction of the asymmetric regulation indicator (at operator level) between a late entrant MNO $i$ with its earlier entrant(s) is the total sum of the product of the difference in MTRs between entrant $i$ with the earlier entrant $j$ multiplied by their relative market shares ${ }^{10}$.

Precisely, the index for the benefits from asymmetric regulation for each late entry operator $i$ at period $t$ is defined as:

$$
A R_{i, t}=\sum_{j}\left[M T R_{i, t}-M T R_{j, t}\right] \frac{\alpha_{i, t}}{\alpha_{j, t}}
$$

where, $\alpha_{i, t}$ and $\alpha_{j, t}$ are respectively the market shares of operator $i$ and $j$, where $j$ enters earlier than $i$, and $M T R_{i, t}$ is the operator $i$ 's mobile termination rate.

${ }^{9}$ Under theoretical assumption of balance calling pattern, the off-net traffics are greatest when both firms have the same market size [4].

${ }^{10}$ This indicator is therefore different to the one proposed by the European regulatory group in the new regulatory draft as their index is mainly driven by the traffic assumptions [1]. 


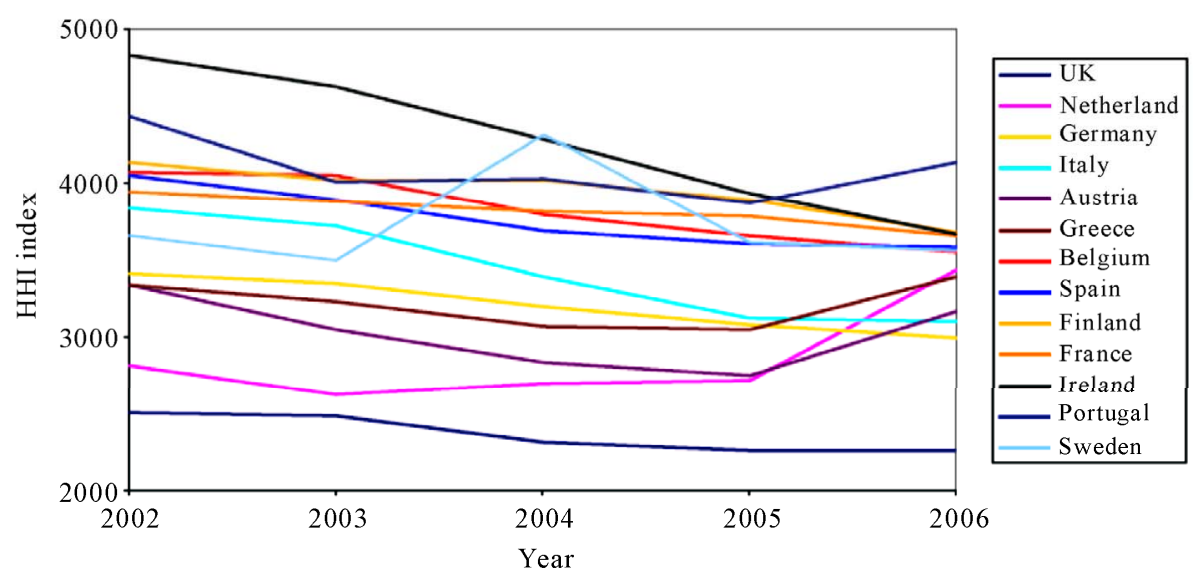

Figure 2. The European mobile market concentration (HHI index) (Source: QUANTIFICA).

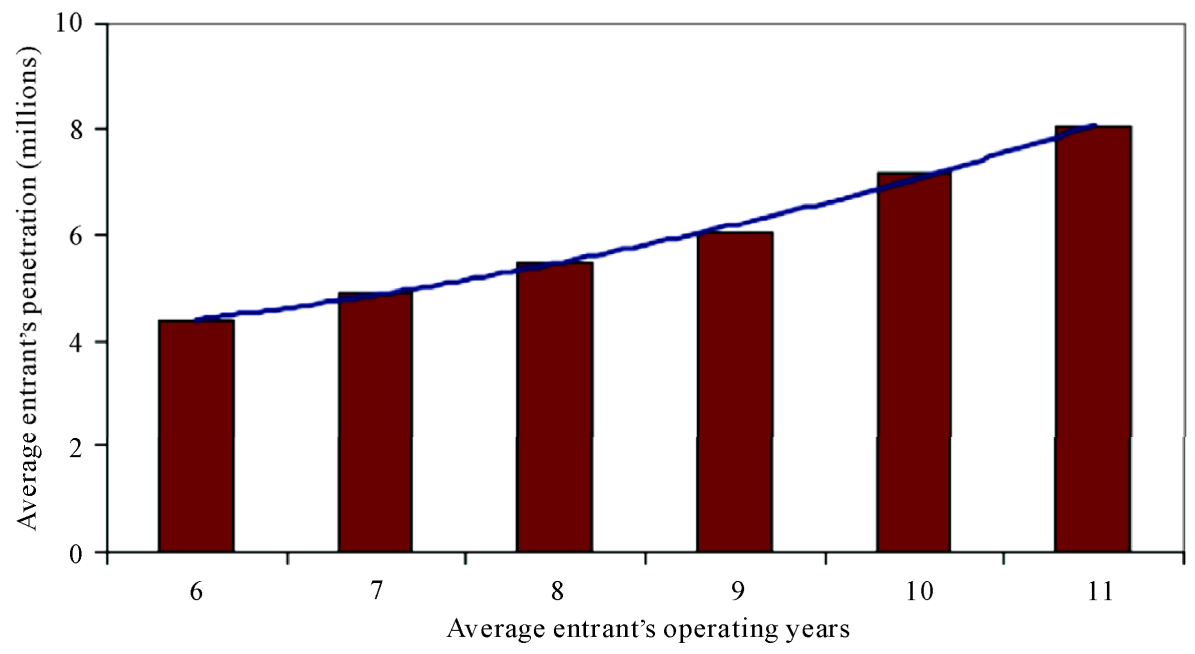

Figure 3. The relationship between the average entrant's operating years and the average entrant's penetration (Source: QUANTIFICA).

The asymmetric regulation indicator at operator level has several remarks. First, due to the fact that later entrants frequently set higher MTRs than earlier entrants and by definition, $A R_{i, t}$ are universally non-negative. Second, a late entrant obtains more from the wholesale market when its relative market shares become larger or when the corresponding relative MTRs are higher. Thus, the value of the indicator becomes zero, representing symmetric regulation, when there is no difference in the level of MTRs among $\mathrm{MNOs}^{11}$. And finally, overall benefits from asymmetric regulation for a later entrant should comprise all individual asymmetric treatments of the later entrant with each individual earlier entrant.

Asymmetric regulation at country level is defined as the average benefit from differences in termination rates between a later entrant and an earlier entrant. Here, the indicator at country level is defined as the ratio of the

\footnotetext{
${ }^{11}$ For example, since 2005 symmetric regulation has been applied in the
} Swedish mobile market. sum of the total benefits from asymmetric regulation for all late entrants in a country to the number of infrastructure MNOs in that country. Conceptually, let us denote $A R_{c, t}$ as the asymmetric regulation indicator for country $c$, then:

$$
A R_{c, t}=\frac{\sum_{i} A R_{i, t}}{n}
$$

where, $A R_{i, t}$ is given by (3) and $n$ is the number of infrastructure MNOs in country $c$.

Figure 4 below shows that despite a clear decreasing trend of MTRs in Europe, the country asymmetric regulation indicator fluctuates across countries and within each country over time. This is because, as already discussed, the entrant's benefits from asymmetric regulation depend not only on setting higher MTRs but also on the relative market shares. A precise illustration is the case of England and France in 2002 and 2003. Although in England, the average difference in MTRs in those two 


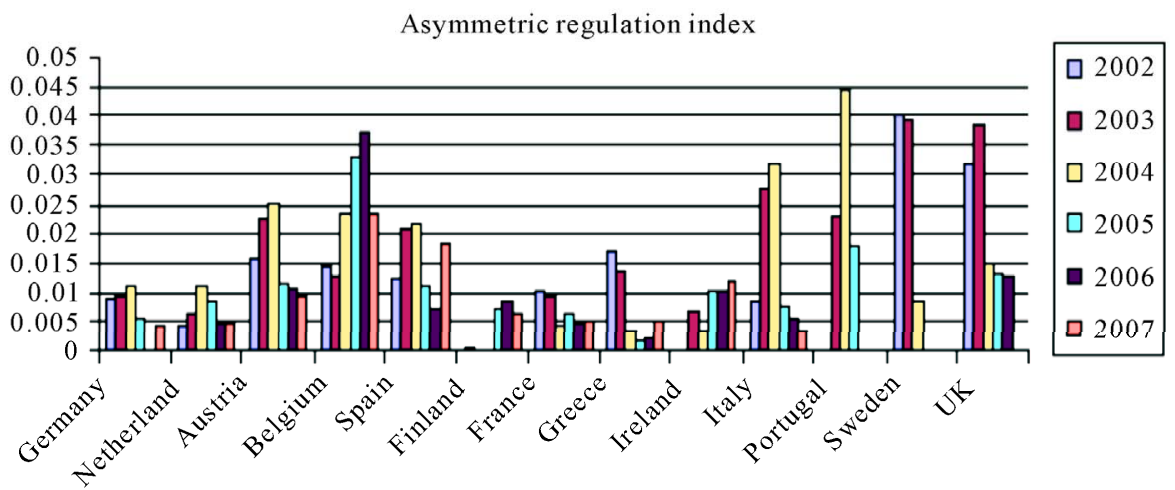

Figure 4. The constructed index of Asymmetric Regulation in the wholesale market at country level.

years was about 3 Euro centimes between the last two entrants and the two earlier entrants, it was about 4 Euro centimes between the last entrant and the two earlier entrants in France. As indicated in Figure 4, the corresponding asymmetric regulation index is, however, more than three times higher for England than it is for France. This is because in England, the market shares of the two later entrants were high, and almost the same as the earlier entrants while in the France's last entrant had only a $16 \%$ market share, and hence a low market position.

\section{Econometric Specifications and Results}

At a theoretical level, MNOs may have several strategies in response to a change in the regulated MTRs and that could affect market competition. In the first subsection, we investigated the impacts of European MTR regulation on entrant penetration. In the second subsection, using similar approach we examine the regulatory effects on market competition proxied by national average service prices.

\subsection{The MTR Regulatory Impacts on Late Entrant Penetration}

There are a number of factors affecting the diffusion of the Europe's mobile telephony in economic studies. For instance, based on a logistic equation, [17] estimates the diffusion rate in the Europe's mobile industry taking into account technological developments and license regulation. In a recent study, [12] explicitly shows that entry timing is an important determinant of the Europe's entrant market share vis a vis incumbent. As an objective of European MTR regulation is to facilitate infrastructure-based competition, this subsection strictly focuses on examining the impacts of MTR regulation on late entrant penetration rather than on market penetration.

Theoretically, the above-cost MTR setting should be beneficial to early entrant with higher market share be- cause of the "tariff mediated effects" [5]. Hence glide path regulation becomes appropriate in this context by reducing this strategic barrier to entry on the one hand. On the other hand, European glide path regulation might have a negative effect on market competition by raising retail price because of a waterbed effect [8]. Precisely, if an entrant had lower wholesale revenue due to lower MTRs (both from fixed and mobile network operators), the operator had to seek more from retail markets possibly by either setting higher retail prices (waterbed effects) or lowering retail prices to gain more subscribers. It seems that the second option is relatively more sustainable for late entrants across Europe's mobile markets. This stems from the following main reasons:

1) Since late entrants often have small markets shares meaning they benefit less from economies of scale, and hence always have strong motivation to increase consumer bases. Furthermore, a large customer base also enhances their reputation, meaning they can gain more subscribers with higher profits in subsequent periods. In addition, since a lower MTR level decreases wholesale revenue especially from the fixed-to-mobile calls, a late entrant has to seek more from retail market revenue which is obviously proportional to its market size. Glide path regulation therefore reinforces the late entrant incentives to compete for more market penetration.

2) Apart from reducing "tariff mediated affects," glide path regulation incites late entrant to undercut retail off-net price to compete for new subscribers without suffering from excessive financial burden transferred to their rivals due to the strategic barrier to entry in retail market and the distorted above-cost MTR setting in wholesale market ${ }^{12}$.

3) Finally, it is obvious that late entrants benefit from a higher subscriber base under the European asymmetric

\footnotetext{
${ }^{12}$ This is exactly the case in France that due to traffic unbalances, the small mobile operator has had to pay to the two big operators the wholesale costs of millions of Euros which could be avoidable if MTRs were regulated at cost.
} 
regulation between MNOs. To clarify this argument, let us take a very simple example in which each mobile user in the small network (i) makes the same amount of off-net calls as he receives from his friends from other networks, let's say one minute ${ }^{13}$. Under asymmetric regulation favouring network $i$, operator $i$ would gain net profits from interconnection for each subscriber, and hence operator $i$ 's total net interconnection profits would raise in the number of mobile users subscribing to its network.

In summary, the basic empirical hypothesis for this subsection is that late entrant MNOs had stronger incentives to boost market penetrations when MTRs were lower. Hence the basic econometric model is as follows:

$$
\operatorname{LnPEN}_{i, t}=\beta_{1}+\beta_{2} \operatorname{LnPEN}_{i, t-1}+\beta_{3} M T R_{i, t}+\varepsilon_{i, t}
$$

where LHS is the penetration rate of the late entrant $M N O_{i}$ at period $t$ in the natural logarithm form, $M T R_{i, t}$ is the operator i's MTRs, and $\operatorname{LnPEN}_{i, t-1}$ is the firm penetration rates lagged order 1 in logarithm form. This proxy is obviously relevant in studying diffusion in the mobile industry [12].

Furthermore, late European entrants are more flexible than earlier entrants in setting MTRs in wholesale markets. Therefore, the indicator of asymmetric regulation at operator level is also employed to control this type of regulation (Model 2A). Finally, the econometric model integrates the number of firm operating years to increase the robustness of the econometric estimation (Model 3A)

$$
\begin{aligned}
\operatorname{LnPEN}_{i, t}= & \beta_{1}+\beta_{2} \operatorname{LnPEN}_{i, t-1}+\beta_{3} M T R_{i, t} \\
& +\beta_{4} A R_{i, t}+\varepsilon_{i, t} \\
\operatorname{LnPEN}_{i, t}= & \beta_{1}+\beta_{2} \operatorname{LnPEN}_{i, t-1}+\beta_{3} M T R_{i, t} \\
& +\beta_{4} A R_{i, t}+Y O E_{i, t}+\varepsilon_{i, t}
\end{aligned}
$$

Where $A R_{i, t}$ is the asymmetric regulation indicator at operator-level, which is constructed in (3), and $Y O E_{i, t}$ is the number of operating years.

The above models are estimated followed fixed effect model framework and with the weighted least square estimation (WLS) method. Furthermore, the estimation allows White heteroskedasticity covariance of the residuals to overcome potential heteroskedasticity problems across sections and because of the indirect correlation between penetration rates and MTRs ${ }^{14}$.

Since there might be problems associated with endogeneity of variables in the RHS, the model also reports the results from estimating the Models (1A), (2A), (3A) with two-stage-least-square estimation method name Model (4A), (5A), (6A) respectively. The common in-

\footnotetext{
${ }^{13}$ This can be considered as a variation of the balance calling pattern assumption which can be found in [4,5].

${ }^{14}$ See the descriptive statistics in the Appendix.
}

strumental variable is average MTRs in Europe during the examined period obtained from QUANTIFICA. This indicator appropriately reflects the trend in MTR regulation in Europe. The other exogenous variables are $M T R_{i, t}$ and $Y O E_{i, t}$.

The result in Table 1 corresponds to the above models. Consistent with all model specifications and estimation methods, the results show that during the examined period, the late entrants' penetration increase rates significantly rose as a result of lower MTRs of late entrant. For instance, in Model (1A), each percent of a decrease in MTRs raises the entrants' penetration rates by 0.36 percent. This rate grows to 0.68 percent after controlling the impact of asymmetric regulation and market competitive pressures in Model 3A or to 1.74 percent with instrumental estimation in Model (5A). This is, as already argued, because the late entrants had strong motivation to increase penetration rates. It is also because when the wholesale revenues, both from rival mobile and fixed operators were reduced due to lower MTRs, the late entrants were likely to seek more from retail markets by enlarging their customer bases.

Concerning the impacts of asymmetric regulation, it can be seen in Table 1 that penetration rates of the late entry operators increased from 2.05 percent (Model 3A) to 3.24 percent (Model 5A) for each centime difference in asymmetric setting of MTRs between late entry and incumbent MNOs. Furthermore, these results detail the success of asymmetric regulation in increasing the entrant' penetration rates market.

Our results indicate that entrant operators gained new subscribers possibly by lowering their service prices or providing higher handset subsidies, or both. Hence, the impact of European MTR regulation on competition in the retail market is empirically investigated in the next subsection.

\subsection{The MTR Regulatory Impacts on National Average Service Prices}

The above finding suggests that European MTR regulation might cause late entrants to compete more aggressively to gain higher penetration, and hence might intensify market competition as early operators have to undercut their prices to response for the late entrant strategies. To test this hypothesis, the link between operator retail prices and their MTRs should be investigated. As it is noted above that obtaining individual prices however is not possible. An alternative indicator is to choose average service prices in European countries provided by QUANTIFICA and investigate the impact of MTR regulation on this indicator. If lowering MTRs increased late entrant incentives to decrease their retail prices and hence 
Table 1. The MTR regulatory impacts on late entrant penetration.

\begin{tabular}{|c|c|c|c|c|c|c|}
\hline \multirow{2}{*}{ Penetration rates LnPEN } & \multicolumn{3}{|c|}{$\begin{array}{l}\text { Fixed effects models with weighted Least square } \\
\text { estimation }\end{array}$} & \multicolumn{3}{|c|}{ Fixed effects models with Instrumental estimation } \\
\hline & Model 1A & Model 2A & Model 3A & Model 4A & Model 5A & Model 6A \\
\hline Penetration lagged order 1 LnPEN (-1) & $0.76(0.00)$ & $0.70(0.00)$ & $0.64(0.00)$ & $0.76(0.00)$ & $0.70(0.00)$ & $0.63(0.00)$ \\
\hline Glidepath regulation MTR & $-0.36(0.02)$ & $-1.52(0.00)$ & $-0.68(0.03)$ & $-0.35(0.02)$ & $-1.74(0.00)$ & $-0.72(0.02)$ \\
\hline Asymmetric regulation $\mathbf{A R}$ & & $2.76(0.00)$ & $2.05(0.00)$ & & $3.24(0.00)$ & $2.11(0.00)$ \\
\hline Number of operating years YOE & & & $0.03(0.00)$ & & & $0.03(0.01)$ \\
\hline
\end{tabular}

P-values are reported in parenthesis signs; Software package: Eviews.

to reinforce competitive pressures among different market players, it could be expected a positive relationship between average market service prices and glide path regulation. As in the previous subsection, we also incorporate our constructed asymmetric regulation index at national level to control for the presence of MTR asymmetric regulation between European MNOs.

In precision, the basic empirical equation of the effects of MTR regulation on the competitiveness of European mobile markets can be expressed in the following regression:

$$
P_{c, t}=\beta_{1}+\beta_{2} P_{c, t-1}+\beta_{3} \text { Average }{ }_{-} M T R_{c, t}+\varepsilon_{c, t}
$$

where LHS is the average service price of the country $c$ at time $t$ in the natural logarithm form and, the Average_MTR $R_{i, t}$ is the average MTR in country $c$ at time $t$ in the natural logarithm form ${ }^{15}$.

As before, the asymmetric regulation indicator at country leve $\mathrm{l}^{16}$ is also employed and the model becomes:

$$
\begin{aligned}
P_{c, t}= & \beta_{1}+\beta_{2} P_{c, t-1}+\beta_{3} \text { Average_MTR } R_{c, t} \\
& +\beta_{4} A R_{c, t}+\varepsilon_{c, t}
\end{aligned}
$$

Moreover, the market concentration variable (HHI index) is included in the above model with the expectation that the lower the HHI index decreased average country service prices.

$$
\begin{aligned}
P_{c, t}= & \beta_{1}+\beta_{2} P_{c, t-1}+\beta_{3} \text { Average }-M T R_{c, t} \\
& +\beta_{4} A R_{c, t}+\beta_{5} \operatorname{Ln}(H H I)_{c, t}+\varepsilon_{c, t}
\end{aligned}
$$

With the panel data sample, the fixed effect models are estimated. As the previous subsection, the above models are regressed using IV method to overcome potential problems associated with endogeneity of the variables in the RHS. The models are respectively named (4B), (5B) and (6B). For Models (1B), (2B) and (3B), the Pool-least-square estimation method is using to account for the hesteroskedasticity of the data. In the corresponding Models (4B), (5B) and (6B), the two-stageleast-square estimation method is used with the average

\footnotetext{
${ }^{15}$ The indicator (average_MTRs) is constructed in (1).

${ }^{16}$ The indicator $\left(A R_{c, t}\right)$ is constructed in (4).
}

MTRs in thirteen countries as the valid instrument while the exogenous variable is $M T R_{c, t}$ and the predetermined variable is $P_{c, t-1}$.

The results in Table 2 indicate that, as expected, the decrease in MTRs resulted in lower service prices in all the model specifications. Furthermore, the results are significant and consistent with various models and estimation methods: market average service prices were lower when NRAs reduced MTR levels. For example, in Model (3B), one percent of reduction in average MTRs led to a decrease of 0.18 percent in average service prices.

Intuitively, this can be explained by the incentives of late entrant to reduce their service prices to gain more subscribers and price competition from early entrant due to glide path regulation. In this light, the lower levels of MTRs could therefore be seen as an appropriate instrument to intensify competitiveness across European mobile markets. In other words, the waterbed effect logic is not applicable in the context of Europe's mobile markets, and the cost-oriented MTR regulation is sensible to encourage competition between European MNOs.

Regarding the second MTR regulatory instrument, our study shows the asymmetric regulation promotes more aggressive pricing strategy among different sized MNOs. Precisely, the implementation of European asymmetric regulation decreased the average service price with the impact coefficients of 0.31 in Model (3B) or 0.82 in Model (5B). From the previous subsection, this is likely due to the fact that late entrants competed more aggressively in the presence of asymmetric regulation to gain market shares $[13,14]$. Correspondingly, incumbents had to lower retail prices to avoid loss in market shares, resulting in lower retail prices at market level.

Finally, Table 2 indicates that the market concentration significantly affected the market prices, although at a modest level. Concretely, one percent drop in the HHI index could lower service prices by 0.08 percent (Model $6 \mathrm{~B})$. This result is not surprising because of the familiar relationship between the degree of market concentration and market competitiveness proxied by national service prices in this study. 
Table 2. The MTR regulatory impacts on national service prices.

\begin{tabular}{|c|c|c|c|c|c|c|}
\hline \multirow[t]{2}{*}{ Service price $\mathbf{P}$} & \multicolumn{3}{|c|}{$\begin{array}{l}\text { Fixed effects models with weighted Least square } \\
\text { estimation }\end{array}$} & \multicolumn{3}{|c|}{ Fixed effects models with Instrumental estimation } \\
\hline & Model 1B & Model 2B & Model 3B & Model 4B & Model 5B & Model 6B \\
\hline Service price lagged order $1 \mathbf{P}(\mathbf{- 1 )}$ & $0.78(0.00)$ & $0.71(0.00)$ & $0.71(0.00)$ & $0.78(0.00)$ & $0.65(0.00)$ & $0.67(0.00)$ \\
\hline Glidepath regulation MTR & $0.14(0.07)$ & $0.22(0.01)$ & $0.18(0.03)$ & $0.14(0.07)$ & $0.27(0.00)$ & $0.2(0.00)$ \\
\hline Asymmetric regulation $\mathbf{A R}$ & & $-0.39(0.02)$ & $-0.31(0.00)$ & & $-0.82(0.00)$ & $-0.74(0.00)$ \\
\hline Market concentration HHI & & & $0.04(0.12)$ & & & $0.08(0.01)$ \\
\hline
\end{tabular}

P-values are reported in parenthesis signs; Software package: Eviews.

\section{Conclusions}

In the context of the Europe's mobile sector, our study shows that competition for additional market shares was stronger when European NRAs required all MNOs to lower their MTRs. This is because the mobile industry is characterised by high price cost margins and strategic competitive behaviour of late entry operators. This consequently intensifies competitive pressures in Europe's mobile markets as explicitly shown in our study.

Furthermore, it is evident that MTR asymmetric regulation could enhance competition both from static and dynamic perspectives. The latter is associated with increased market share of later entrant which is coincided with the European MTR regulation principles to create more sustainable long-term competition between infrastructures MNOs. In other words, our study provides evidences to support the implementation of current MTR regulation in Europe.

\section{References}

[1] European Commission, "Draft Commission Recommendation on the Regulatory Treatment of Fixed and Mobile Termination Rates in the EU,” Brussels, June 2008.

[2] ERG, "ERG's Common Position on Symmetry of Fixed Call Termination Rates and Symmetry of Mobile Call Termination Rates," ERG (07)83, Final 080312, February 2008.

[3] M. Armstrong, "Network Interconnection in Telecommunications,” Economic Journal, Vol. 108, No. 448, 1998, pp. 545-564. doi:10.1111/1468-0297.00304

[4] J.-J. Laffont, P. Rey and J. Tirole, "Network Competition: I. Overview and Nondiscriminatory Pricing," RAND Journal of Economics, Vol. 29, No. 1, 1998, pp. 1-37. doi:10.2307/2555814

[5] J.-J. Laffont, P. Rey and J. Tirole, "Network Competition: II. Price Discrimination," RAND Journal of Economics, Vol. 29, No. 1, 1998, pp. 38-56. doi:10.2307/2555815

[6] M. Armstrong, "The Theory of Access Pricing and Interconnection,” In M. Cave, S. Majumdar and I. Vogelsang, Eds., Handbook of Telecommunications Economics, El- sevier, North-Holland, 2002, pp. 297-386.

[7] M. Armstrong and J. Wright, "Mobile Call Termination," The Economic Journal, Vol. 119, 2009, pp. 270-307.

[8] J. S. Gans and S. P. King, “Using ‘Bill and Keep’ Interconnection Arrangements to Soften Network Competition," Economic Letters, Vol. 71, No. 3, 2001, pp. 413420. doi:10.1016/S0165-1765(00)00279-2

[9] A. Schiff, "The Waterbed Effect and Price Regulation," Review of Network Economics, Vol. 7, No. 3, 2008, pp. 392-414.

[10] C. Genakos and T. Valletti, "Testing the "Waterbed" Effect in Mobile Telephony," Journal of the European Economic Association, 2011 (Online Version of Record published before inclusion in an issue).

[11] K. Anderson and B. Hansen, "Network Competition: Empirical Evidence on Mobile Termination Charges and Profitability," Mimeo, 2009.

[12] G. E. Bijwaard, C. W. J. Maarten and M. Emiel, "Early Mover Advantages: An Empirical Analysis of European Mobile Phone Markets," Telecommunications Policy, Vol. 32, No. 3-4, 2007, pp. 246-261. doi:10.1016/j.telpol.2007.08.006

[13] M. Peitz, "On Access Pricing in Telecoms: Theory and European Practice," Telecommunications Policy, Vol. 27, No. 10-11, 2003, pp. 729-740. doi:10.1016/j.telpol.2003.06.001

[14] M. Peitz, "Asymmetric Access Price Regulation in Telecommunications Markets," European Economic Review, Vol. 49, No. 2, 2005, pp. 341-358. doi:10.1016/S0014-2921(03)00046-1

[15] M. Peitz, "Asymmetric Regulation of Access and Price Discrimination in Telecommunications," Journal of Regulatory Economics, Vol. 28, No. 3, 2005, pp. 327-343. doi:10.1007/s11149-005-3963-1

[16] T. Valletti, "Asymmetric Regulation of Mobile Termination Rates," 2006. www.npt.no/iKnowBase/Content/100464/Vedlegg_Telen or.pdf.

[17] H. Gruber and F. Verboven, "The Diffusion of Mobile Telecommunications Services in the European Union Countries,” European Economic Review, Vol. 45, No. 3, 2001, pp. 577-588. doi:10.1016/S0014-2921(00)00068-4 


\section{Appendix}

The basic descriptive statistic.

\begin{tabular}{lcccc}
\hline \multicolumn{1}{c}{ Data } & Mean & Max & Min & Sta. Dev \\
\hline Competitiveness index (HHI) & 3502.52 & 4831.72 & 2252.70 & 577.93 \\
Service Prices (P) & 0.22 & 0.37 & 0.09 & 0.06 \\
Mobile Termination Rates (MTR) & 0.15 & 0.32 & 0.06 & 0.05 \\
Operating Years (YOE) & 8.30 & 19.00 & 1.00 & 3.46 \\
penetration (PEN) (in thousands) & 5815.02 & 29997.40 & 95.00 & 5951.68 \\
\hline
\end{tabular}

Twenty five MNOs with a late market entrance.

\begin{tabular}{ccc}
\hline Base & One & Telfort \\
\hline Elisa & TMobile Austria & Optimus \\
E-plus & Telering & Vodafone Portugal \\
Vodafone Italy & Meteor & Tele2 Mobil \\
Wind Italy & Wind-Hellas & Telenor Sweden \\
Vodafone Spain & Orange Netherlands & O2 Ireland \\
Amena & TMobile Netherlands & Mobistar \\
Bouygues Telecom & Orange UK & \\
\hline
\end{tabular}

